\title{
Article
}

\section{Isotopic exchange of oxygen, sulfur, hydrogen and copper between aqueous phase and the copper minerals brochantite, libethenite and olivenite}

\author{
Juraj Majzlan ${ }^{1 \star}$ (D), Ryan Mathur ${ }^{2}$, Rastislav Milovský ${ }^{3}$ and Stanislava Milovská ${ }^{3}$ \\ ${ }^{1}$ Institute of Geosciences, Friedrich-Schiller University, Burgweg 11, 07749 Jena, Germany; ${ }^{2}$ Department of Geology, Juniata College, 1700 Moore St, Huntingdon, \\ PA, 16652, USA; and ${ }^{3}$ Earth Science Institute, Slovak Academy of Sciences, Duumbierska 1, SK-974 11, Banská Bystrica, Slovakia
}

\begin{abstract}
Fractionation factors for the isotopes of $\mathrm{O}, \mathrm{H}, \mathrm{S}$, or $\mathrm{Cu}$ (as appropriate) were determined for the minerals brochantite $\left[\mathrm{Cu}_{4}\left(\mathrm{SO}_{4}\right)\left(\mathrm{OH}_{6}\right]\right.$, libethenite $\left[\mathrm{Cu}_{2}\left(\mathrm{PO}_{4}\right)(\mathrm{OH})\right]$ and olivenite $\left[\mathrm{Cu}_{2}\left(\mathrm{AsO}_{4}\right)(\mathrm{OH})\right]$ and corresponding aqueous solutions at temperatures between 30 and $70^{\circ} \mathrm{C}$. All samples used for this determination were synthetic and the degree of fractionation was expressed as $1000 \ln \alpha=\left(A \times 10^{6} / T^{2}\right)+B$, where $A$ and $B$ are empirical parameters. A few natural libethenite samples from its type locality Lubietová-Podlipa were also analysed and compared to the prediction based on the isotopic composition of meteoric water and our fractionation factors. The hydrogen fractionation factors agreed with the prediction well, whereas those for oxygen did not. A possible explanation is the disequilibrium of aqueous phosphate (and also arsenate) species and the solution in our experiments or the interaction of meteoric fluids with the isotopically heavy (in terms of oxygen) country rocks. Because the effects of isotopic disequilibrium in our experiments cannot be ruled out, the oxygen fractionation factors should be used with caution. The determined fractionation factors can be used as an isotope geothermometer, given that it can be proven that the phases of interest precipitated from the same fluid in equilibrium. Libethenite is predicted to have slightly lower $\delta^{65} \mathrm{Cu}$ values than its parental solution, but brochantite slightly higher $\delta^{65} \mathrm{Cu}$ values than its parental solution. Simple forward models, simulating neutralisation or reduction of mine drainage, show that precipitation of these minerals and removal of the co-existing fluid, could cause isotopic variations (in $\delta^{65} \mathrm{Cu}$ ) on the order of $1 \%$ or more.
\end{abstract}

Keywords: libethenite, olivenite, brochantite, isotopes, fractionation factors

(Received 20 July 2021; accepted 11 October 2021; Accepted Manuscript published online: 18 October 2021; Associate Editor: Peter Leverett)

\section{Introduction}

Copper sulfate, phosphate and arsenate minerals are common constituents of many oxidation zones of ore deposits (e.g. Williams, 1990), mine wastes and tailings (Sracek et al., 2010; Portales et al., 2015), or oxidation products of copper artefacts (e.g. Livingston, 1991; Karlén et al., 2002). Their formation and fate are to a certain extent controlled by equilibrium thermodynamics. Chemical reactions, such as precipitation or transformation, determine which minerals form or persist (e.g. Magalhães et al., 1986, 1988; Bowell, 2014). The distribution of substituting ions between the aqueous phase and solid solution is controlled by mixing parameters (e.g. Glynn, 1991, 2000), expressed graphically by the Lippmann diagrams (Lippmann, 1980). A special

\footnotetext{
${ }^{*}$ Author for correspondence: Juraj Majzlan, Email: juraj.majzlan@uni-jena.de This paper is part of a thematic set that honours the contributions of Peter Williams Cite this article: Majzlan J., Mathur R., Milovský R. and Milovská S. (2022) Isotopic exchange of oxygen, sulfur, hydrogen and copper between aqueous phase and the copper minerals brochantite, libethenite and olivenite. Mineralogical Magazine 86, 644-651. https://doi.org/10.1180/mgm.2021.77
}

type of distribution is the one that involves isotopes of one element, partitioned among co-existing phases (Sharp, 2017). This distribution is associated with significantly smaller energies than chemical equilibria between aqueous and pure solid phases or equilibria that involve solid solutions (Sharp, 2017, page 3-3). Despite such tiny energy changes, the isotopic equilibria are instrumental in many areas of geosciences as they can reveal details about the geological history of various samples, their temperature of formation, or the origin of the parental solutions.

In this work, we have determined isotopic fractionation factors for $\mathrm{H}, \mathrm{O}, \mathrm{S}$ and $\mathrm{Cu}$ between an aqueous phase and the minerals brochantite $\left[\mathrm{Cu}_{4}\left(\mathrm{SO}_{4}\right)(\mathrm{OH})_{6}\right]$, libethenite $\left[\mathrm{Cu}_{2}\left(\mathrm{PO}_{4}\right)(\mathrm{OH})\right]$ and olivenite $\left[\mathrm{Cu}_{2}\left(\mathrm{AsO}_{4}\right)(\mathrm{OH})\right]$. They were selected as common representatives of the copper sulfate, phosphate and arsenate minerals, respectively, in environments where there is weathering of copper ores or their products. All three minerals were synthesised under controlled conditions in the laboratory at various temperatures and their isotopic composition was determined by mass spectrometry. A few natural libethenite samples were analysed together with the suite of synthetic samples and the isotopic

(C) The Author(s), 2021. Published by Cambridge University Press on behalf of The Mineralogical Society of Great Britain and Ireland. This is an Open Access article, distributed under the terms of the Creative Commons Attribution licence (http://creativecommons.org/licenses/by/4.0/), which permits unrestricted re-use, distribution and reproduction, provided the original article is properly cited. 
composition of their parental waters was estimated from the newly determined fractionation factors. Simple chemical forward models were coupled with isotopic fractionation factors for copper to document possible fluctuations in the $\mathrm{Cu}$ isotopic composition of aqueous fluids at near-surface temperatures.

\section{Materials}

\section{Syntheses of olivenite and libethenite}

Preliminary syntheses of both phases were carried out at $30-80^{\circ} \mathrm{C}$ to determine the optimal conditions, phase-pure yield, and the amount of chemicals needed to carry out the syntheses successfully. For the syntheses of olivenite and libethenite, the following chemicals were used: $\mathrm{Cu}\left(\mathrm{NO}_{3}\right)_{2} \cdot 3 \mathrm{H}_{2} \mathrm{O}, \mathrm{Na}_{2} \mathrm{HAsO}_{4} \cdot 7 \mathrm{H}_{2} \mathrm{O}$, $\mathrm{NaH}_{2} \mathrm{PO}_{4} \cdot 2 \mathrm{H}_{2} \mathrm{O}$ and $\mathrm{NaOH}$. At the beginning of the experiments, $1.566 \mathrm{~g} \mathrm{Cu}\left(\mathrm{NO}_{3}\right)_{2} \cdot 3 \mathrm{H}_{2} \mathrm{O}$ and $1.01098 \mathrm{~g} \mathrm{Na}_{2} \mathrm{HAsO}_{4} \cdot 7 \mathrm{H}_{2} \mathrm{O}$ (for olivenite) and $1.566 \mathrm{~g} \mathrm{Cu}\left(\mathrm{NO}_{3}\right)_{2} \cdot 3 \mathrm{H}_{2} \mathrm{O}$ and $0.5054 \mathrm{~g} \mathrm{NaH}_{2} \mathrm{PO}_{4} \cdot 2 \mathrm{H}_{2} \mathrm{O}$ (for libethenite) were weighed. Each chemical was dissolved separately in $10 \mathrm{~mL}$ of deionised water. In addition, a stock solution of $0.3 \mathrm{M} \mathrm{NaOH}$ was prepared.

The prepared solutions were heated separately in borosilicate flasks to the desired temperature on a heating plate. Once the temperature was reached and stabilised, the phosphate/arsenate solution was poured into the copper solution. A light blue precipitate formed immediately and remained in the mixture. The solutions were strongly acidic, $\approx 2.2$ for $\mathrm{Cu} / \mathrm{As}$ and $\approx 2.6$ for $\mathrm{Cu} / \mathrm{P}$. The stock $\mathrm{NaOH}$ solution was used to adjust $\mathrm{pH}$ to 3.0 , using a $\mathrm{pH}$ electrode.

The suspensions were placed in heating cabinets at a constant temperature. One week was sufficient for temperatures 50 to $80^{\circ} \mathrm{C}$. At $30^{\circ} \mathrm{C}$, the time necessary to reach a crystalline product was $\sim 3$ weeks. Thereafter, the solutions remained clear, with light blue colour. The product was green (libethenite) or light-green to beige (olivenite). The solid was filtered, washed with deionised water, and air dried.

The samples for the determination of isotopic fractionation factors were synthesised in a similar manner. For their syntheses, however, larger volumes of stock solutions of all chemicals were prepared before the start of the experiments and were stored tightly sealed in borosilicate $(\mathrm{Cu}, \mathrm{P}$ and As solution) or plastic ( $\mathrm{NaOH}$ solution) bottles. The goal was to maintain a constant isotopic composition of the parental solutions for all of the experiments. The volume of the $\mathrm{NaOH}$ solution, necessary to raise $\mathrm{pH}$ to 3.0, was determined in the preliminary experiments. During this experiment series, $\mathrm{pH}$ was not monitored. The flasks were placed in a thermostat with temperature control precision of $\pm 0.5^{\circ} \mathrm{C}$, with a set point between 30 and $70^{\circ} \mathrm{C}$ with $10^{\circ} \mathrm{C}$ steps.

\section{Syntheses of brochantite}

Preliminary syntheses of brochantite were carried out in the temperature range 40 to $80^{\circ} \mathrm{C}$ with a step of $5^{\circ} \mathrm{C}$. For these syntheses, the following chemicals were used: $\mathrm{CuSO}_{4} \cdot 5 \mathrm{H}_{2} \mathrm{O}$ and $\mathrm{NaOH}$. Initially, 0.04 grams of $\mathrm{CuSO}_{4} \cdot 5 \mathrm{H}_{2} \mathrm{O}$ and 0.32 grams of $\mathrm{NaOH}$ were weighed out. Each chemical was dissolved separately in $40 \mathrm{~mL}$ deionised water to produce $0.004 \mathrm{M} \mathrm{CuSO}_{4}$ and $0.2 \mathrm{M} \mathrm{NaOH}$ solutions.

The solutions were heated separately on a heating plate to the desired temperature. After the temperature was reached and stabilised, the $\mathrm{NaOH}$ solution was added dropwise up to $\mathrm{pH}$ of 6.2. During this titration, turquoise precipitate formed immediately and did not re-dissolve. Once the end $\mathrm{pH}$ was reached, the suspension was filtered through filter paper and the filtrate allowed to air dry.

The samples for the determination of isotopic fractionation factors were synthesised in a similar manner. Larger volumes of stock solutions were prepared and used throughout these syntheses, but in a thermostat with temperature control to $\pm 0.5^{\circ} \mathrm{C}$. The stock solutions were $0.08 \mathrm{M} \mathrm{CuSO}_{4}$ and $0.3 \mathrm{M} \mathrm{NaOH}$ solution.

\section{Natural samples}

A few natural samples were collected near the village of Lubietová, at a site called Podlipa. This site is the type locality of libethenite and this mineral, together with other phosphates and carbonates of copper, can be found in abundance in the old mining dumps. The samples used in this study were grab samples with visible libethenite crystals and druses. The precise location of these samples in the oxidation zone at Lubietová-Podlipa is not known.

\section{Methods}

Powder X-ray diffraction ( $\mathrm{pXRD}$ ) patterns of all samples were collected with a Bruker D8 Advance DaVinci diffractometer employing $\mathrm{CuK \alpha}$ radiation $(\lambda=1.54058 \AA)$. The patterns were collected at room temperature between 5 and $90^{\circ} 2 \theta$, with a step size of $0.02^{\circ} 2 \theta$, and a time per step of $1.0 \mathrm{~s}$.

Oxygen isotopes were measured on an isotope ratio mass spectrometer (IRMS) MAT253 at the Slovak Academy of Sciences, Banská Bystrica, Slovakia, using an automated carbonate preparation system (KIEL IV) coupled to IRMS in dual-inlet mode. Powdered samples of $\approx 100 \mu \mathrm{g}$ were heated overnight at $70^{\circ} \mathrm{C}$ in order to remove adsorbed water. The samples were then reacted with anhydrous $\mathrm{H}_{3} \mathrm{PO}_{4}$ at $70^{\circ} \mathrm{C}$ in a vacuum. The $\mathrm{CO}_{2}$ yield was purified through two liquid nitrogen traps and introduced into the IRMS. Raw isotope values were calibrated using international reference material NBS18 with $\delta^{18} \mathrm{O}=-23.2 \%$ and two working standards with $\delta^{18} \mathrm{O}=-2.40 \%$ and $\delta^{18} \mathrm{O}=-15.30 \%$. The precision of the method is $0.02 \%$ for $\delta^{18} \mathrm{O}$ (based on measurements in this work). The measured values are reported as $\delta^{18} \mathrm{O}_{\text {VsMow }}$.

Hydrogen isotopes were measured using an elemental analyser (FLASH 2000 HT plus) coupled to the IRMS in continuous-flow mode. Powdered samples of ca. 250-700 $\mu \mathrm{g}$ were filled into silver capsules and pyrolysed on glassy-carbon chips in a stream of helium at $1400^{\circ} \mathrm{C}$. Evolved $\mathrm{H}_{2}$ was purified from other gases on a packed chromatographic column ( $5 \AA$ molecular sieve) and led into IRMS. The $\delta \mathrm{D}$ values were calibrated by international reference materials USGS 57 and USGS 58 with $\delta \mathrm{D}=-91.5 \pm 2.4$ and $-28.4 \pm 1.6 \%$, respectively (Qi et al., 2017). The precision of the method is $3 \%$ o for $\delta \mathrm{D}$, values are reported as $\delta \mathrm{D}_{\text {VSMow }}$.

Sulfur isotopes were measured on a mass spectrometer MAT253 coupled with the elemental analysis device Flash2000 HT plus (Thermo Scientific) in a continuous-flow mode. Powdered samples of ca. 800-950 $\mu$ g of brochantite were wrapped into tin capsules with the same amount of $\mathrm{V}_{2} \mathrm{O}_{5}$. After flushing with helium, they were combusted in a packed quartz glass reactor at $1000^{\circ} \mathrm{C}$ in a stream of oxygen. Evolved gases were carried by helium through $\mathrm{WO}_{3}$ and copper for purification, magnesium perchlorate for water trapping and chromatographic column for separation of $\mathrm{SO}_{2}$ from other gases, and further into mass spectrometer. The sample $\mathrm{SO}_{2}$ peak was preceded by two injections of reference $\mathrm{SO}_{2}$ gas against which the isotope composition is 
measured. Raw values were corrected by four-point calibration using international standards IAEA-S2, IAEA-S3, IAEA-SO6 and NBS-127 with $\delta^{34} \mathrm{~S}$ values $+22.70,-32.30,-34.10$ and $+20.30 \%$ o CDT, respectively. All the values are reported as per mil versus CDT, long-term external precision is $0.21 \%$.

Copper isotopes were measured on a Neptune plus multicollector mass spectrometer at Washington State University. As all the solid and solutions analysed were copper rich, no ion exchange chromatography was needed (Mathur et al., 2005; Zhang et al., 2020; Zhu et al., 2000). Solids were dissolved in $4 \mathrm{ml}$ of ultrapure aqua regia in $15 \mathrm{ml}$ Teflon vials that were heated to $80^{\circ} \mathrm{C}$ overnight. Solutions were diluted to $150 \mathrm{ppb} \mathrm{Cu}$ and measured in wet plasma mode in low resolution. Mass bias was corrected for using standard sample bracketing with NIST 976. All values are reported relative to the NIST 976 in the traditional per mil unit (\%). Blanks on-peak were subtracted, one block of 35 ratios was measured and values were measured in duplicate. All duplicates fell within error reported below. An internal USA cent standard produced $\delta^{65} \mathrm{Cu}=+0.02 \pm 0.06 \%$ o $(2 \sigma, n=12)$ and lies within error of previously reported values in Mathur et al. (2009). The NIST 976 standard varied by $\pm 0.08 \%$ o $(n=46)$ and is considered the conservative estimate of the error for the analyses.

\section{Results}

The samples synthesised for the investigation of isotopic fractionation were phase-pure, with sharp XRD peaks (see Supplementary Fig. S1). The refined lattice parameters show no correlation with the synthesis temperature, as expected (Tables 1-3). Examination of the samples, either in air or in oil suspensions, under transmitted polarised light showed no impurities (Fig. 1a). The synthetic protocols were optimised in a number of experiments, many of them yielding mixtures of phases (Fig. 1b). The material used in this study, however, was free of impurities.

Infrared and Raman spectroscopy (Supplementary Figs S2-S4) confirmed the absence of impurities. The spectral features could all be assigned to the mineral that was synthesised. There were no significant differences among the spectra of individual minerals when synthesised at different temperatures.

\section{Isotopic composition of synthetic and natural samples}

The isotopic composition of the solutions used for the syntheses of the phases considered here is listed in Table 4. All starting solutions were prepared from deionised water and the variations in the $\delta \mathrm{D}$ and $\delta^{18} \mathrm{O}$ values are due to the isotopic composition of the dissolved solids. The difference is especially marked for the $\mathrm{Cu}\left(\mathrm{NO}_{3}\right)_{2}$ solution. This chemical, as are many nitrates, is hygroscopic and was absorbing water vapour from the air over longer periods of time. For the calculation of the starting isotopic composition (for $\mathrm{O}$ and $\mathrm{H}$ ), we used weighted averages of the values in Table 4, according to the synthesis protocols.

The isotopic compositions of the solid products are listed in Tables 1-3. The measured isotopic composition for the individual phases considered in this work is plotted in Fig. 2 in 1000/T versus $1000 \ln \alpha$ space. The results of the linear fits, including uncertainties, are given in Table 5.

The isotopic composition of the libethenite samples from the dumps at Lubietová-Podlipa is listed in Table 6. The samples show some scatter but, because they originate from the old dumps, that scatter cannot be correlated to the position of these samples in the oxidation zone.

\section{Discussion}

\section{The role of precursors and isotopic equilibrium}

The syntheses performed in this work shared a common feature that after initial and rapid mixing of the solutions, fine-grained precipitate formed and slowly transformed to the final product. The nature of the precipitate was not investigated further. For malachite, Melchiorre et al. (1999) and Plumhoff et al. (2021) showed that the initial precipitate in rapid syntheses is georgeite, a poorly-crystalline precursor of malachite. Thus, it must be asked whether the measured isotopic composition reflects a true equilibrium between the crystalline solids and the fluids, or if it was inherited to some extent from the precursor. It has been suggested previously that the isotopic composition may be influenced by the degree of crystallinity (O’Neil et al., 1969). For malachite, Plumhoff et al. (2021) were able to show that the precursor signature persists at $<50^{\circ} \mathrm{C}$ over the duration of the experiments. At higher temperatures, the isotopic equilibrium was reached rapidly. Melchiorre et al. (1999) discussed the possible impact of the precursors on the $\delta^{18} \mathrm{O}$ values between carbonates and solutions. Both positive and negative deviations from the equilibrium fractionation can be encountered.

Many supergene minerals precipitate from gel-like precursors (O’Neil et al., 1969, Melchiorre et al., 1999, Majzlan, 2020), and not directly from the aqueous solutions. If the formation of these precursors and their transformation to the crystalline phases are alike in the laboratory and Nature, then the fractionation factors used in this work can be used to model and understand natural processes. Conversely, it should be noted that if the formation mechanism in Nature differs from that in laboratory, our results may not be fully applicable to such natural systems.

\section{Isotopic composition in relation to the parental fluid}

The investigated minerals form in near-surface environments, during weathering of ore minerals. Therefore, the most common parental solution, from which they precipitate, is rain water. Other parental solutions are rare but known (e.g. marine water at Lavrion, Greece, Siidra et al., 2011) or low-temperature hydrothermal solutions (Haßler et al., 2014).

The relationship between the isotopic composition of $\mathrm{H}$ and $\mathrm{O}$ in rain water expresses the Global Meteoric Water Line (GMWL)

$$
\delta D_{\text {rain water }}=8 \delta^{18} \mathrm{O}_{\text {rain water }}+10
$$

The difference between the isotopic composition of a mineral and its parental solution, assuming only equilibrium fractionation, is

$$
\delta D_{\text {mineral }}-\delta D_{\text {solution }} \approx 1000 \ln \alpha_{\text {mineral-solution }}^{\text {hydrogen }}
$$

and

$$
\delta^{18} \mathrm{O}_{\text {mineral }}-\delta^{18} \mathrm{O}_{\text {solution }} \approx 1000 \ln \alpha_{\text {mineral-solution }}^{\text {oxygen }}
$$

Combining and re-arranging equations (1), (2) and (3) gives

$$
\begin{aligned}
\delta D_{\text {mineral }}= & 8 \delta^{18} \mathrm{O}_{\text {mineral }}+10 \\
& +\left(1000 \ln \alpha_{\text {mineral-solution }}^{\text {hydrogen }}-8 \times 1000 \ln \alpha_{\text {mineral-solution }}^{\text {oxygen }}\right)
\end{aligned}
$$


Table 1. Isotopic composition and lattice parameters $\left(a, b, c\right.$ in $\AA, \beta$ in ${ }^{\circ}, \mathrm{V}$ in $\left.\AA^{3}\right)$ of brochantite samples synthesised at various temperatures. Space group $P 12_{1} / a 1$.

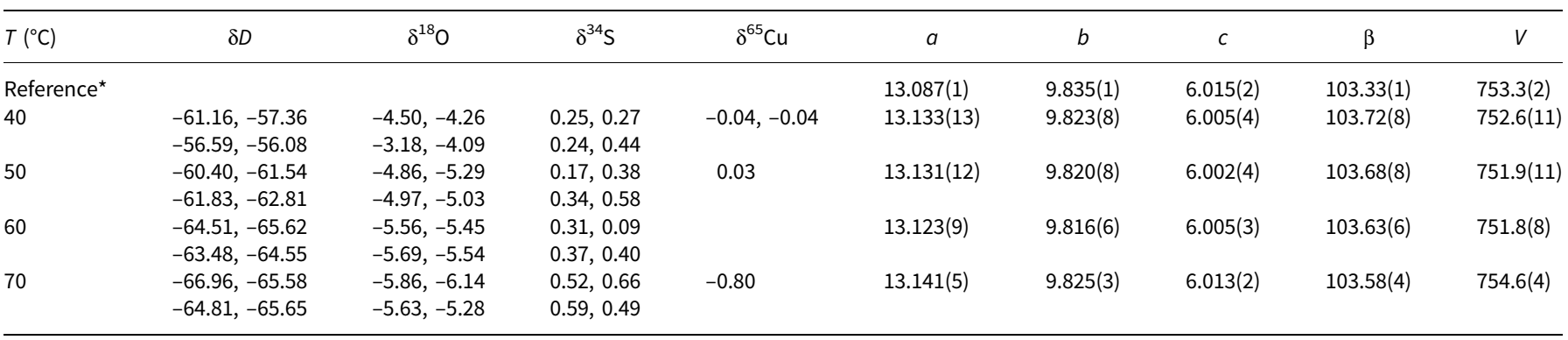

*The reference structural model is taken from Helliwell and Smith (1997).

Table 2. Isotopic composition and lattice parameters $\left(a, b, c\right.$ in $\AA, V$ in $\left.\AA^{3}\right)$ of the libethenite samples synthesised at various temperatures. Space group Pnnm.

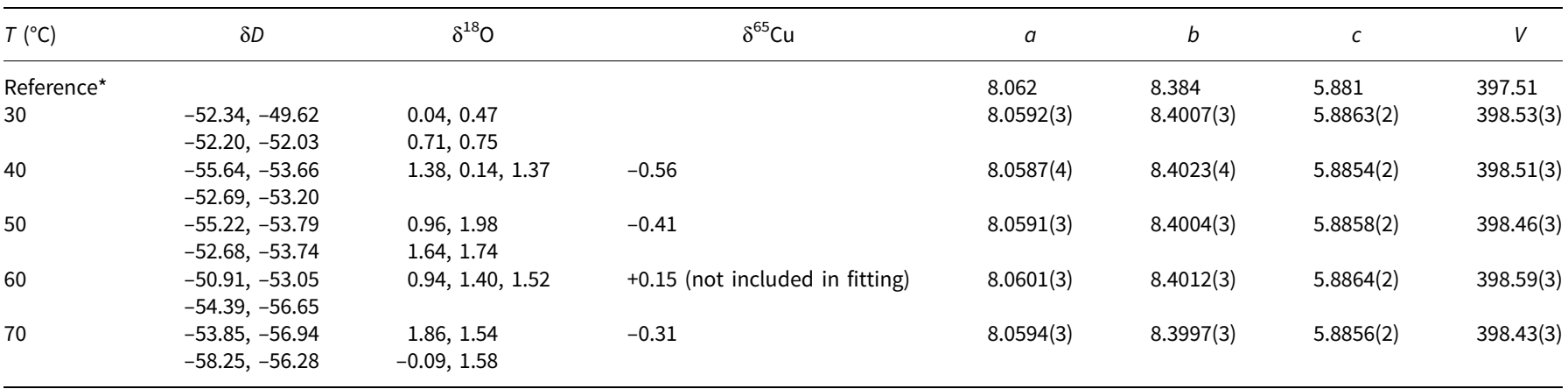

*The reference structural is model taken from Cordsen (1978).

Table 3. Isotopic composition and lattice parameters $\left(a, b, c\right.$ in $\AA$, $\alpha$ in ${ }^{\circ}, V$ in $\left.\AA^{3}\right)$ of the olivenite samples synthesised at various temperatures. Space group $P 2_{1} / n 11$.

\begin{tabular}{|c|c|c|c|c|c|c|c|}
\hline$T\left({ }^{\circ} \mathrm{C}\right)$ & $\delta D$ & $\delta^{18} O$ & $a$ & $b$ & $c$ & $\alpha$ & $V$ \\
\hline Reference $^{\star}$ & & & 8.5844 & 8.2084 & 5.9258 & 90.130 & 417.556 \\
\hline 30 & $\begin{array}{l}-57.02,-58.40 \\
-58.39,-58.97\end{array}$ & $\begin{array}{l}-5.70,-6.47 \\
-6.03,-6.07\end{array}$ & $8.6420(7)$ & $8.2395(7)$ & $5.9396(5)$ & $90.155(7)$ & $422.93(6)$ \\
\hline 40 & $\begin{array}{l}-58.12,-56.39 \\
-57.58,-54.32\end{array}$ & $\begin{array}{l}-7.04,-7.00 \\
-6.45,-5.89\end{array}$ & $8.6343(4)$ & $8.2348(5)$ & $5.9362(3)$ & $90.155(4)$ & $422.07(4)$ \\
\hline 50 & $\begin{array}{l}-59.17,-56.57 \\
-56.37,-60.34\end{array}$ & $\begin{array}{l}-7.48,-7.60 \\
-7.72,-7.62\end{array}$ & $8.6319(3)$ & $8.2350(4)$ & $5.9358(3)$ & $90.150(4)$ & $421.94(3)$ \\
\hline 60 & $\begin{array}{l}-62.23,-63.65 \\
-63.56,-62.74\end{array}$ & $\begin{array}{l}-8.76,-8.48 \\
-8.04,-8.00\end{array}$ & $8.6335(4)$ & $8.2349(5)$ & $5.9337(3)$ & $90.159(5)$ & $421.86(4)$ \\
\hline 70 & $\begin{array}{l}-64.30,-62.65 \\
-61.81,-64.42\end{array}$ & $\begin{array}{l}-9.29,-9.31 \\
-9.34,-9.49\end{array}$ & $8.6289(4)$ & $8.2310(5)$ & $5.9337(3)$ & $90.164(5)$ & $421.43(4)$ \\
\hline
\end{tabular}

*The reference structural model is taken from Li et al. (2008).

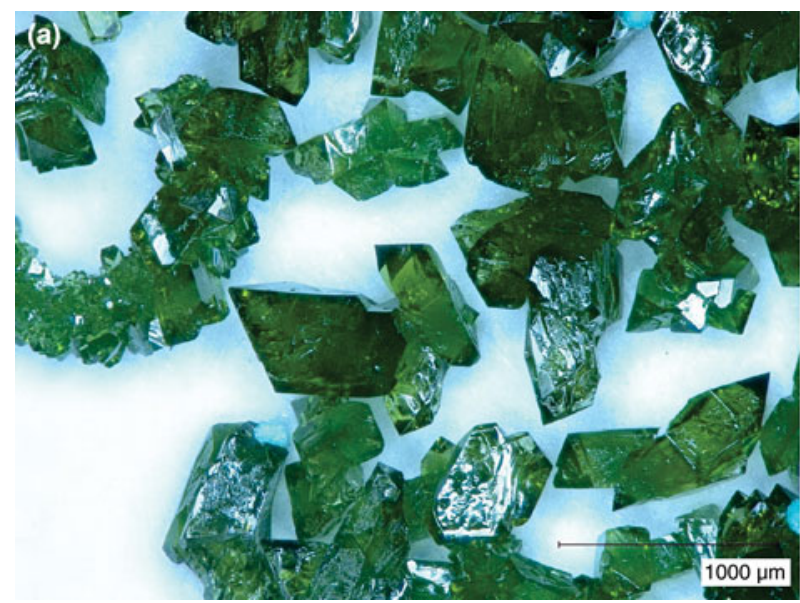

(b)

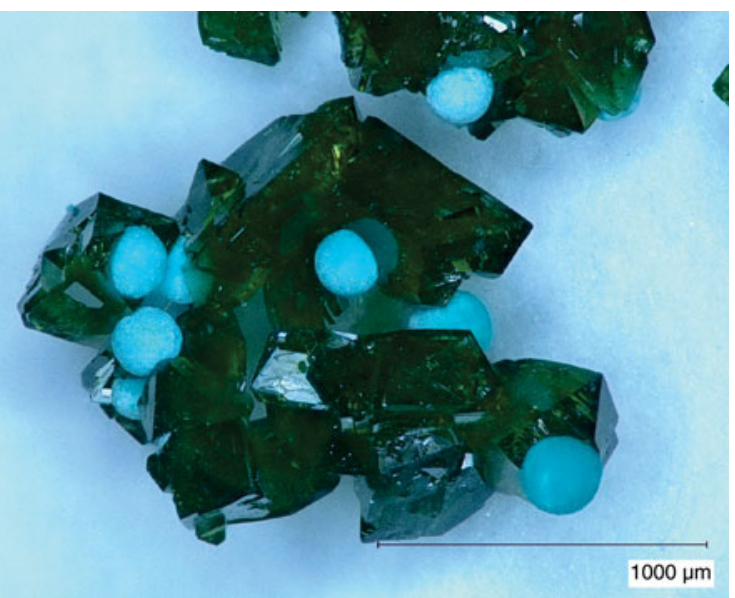

Fig. 1. Photographs of synthesis products from a binocular microscope. (a) Libethenite crystals, phase-pure sample; (b) libethenite crystals contaminated by spherical aggregates of pseudomalachite. 
Table 4. Isotopic composition of the solutions used for syntheses of brochantite, libethenite and olivenite.

\begin{tabular}{lcccc}
\hline Solution & $\delta \mathrm{D}$ & $\delta^{18} \mathrm{O}$ & $\delta^{65} \mathrm{Cu}$ & $\delta^{34} \mathrm{~S}$ \\
\hline Deionised water & $-60.49 \pm 0.08$ & $-8.32 \pm 0.17$ & & \\
$\mathrm{Cu}\left(\mathrm{NO}_{3}\right)_{2}$ solution & $-65.4 \pm 0.7$ & $-6.22 \pm 1.05$ & $-0.37,-0.32$ & \\
$\mathrm{Na}_{2} \mathrm{HAsO}_{4}$ solution & $-57.3 \pm 0.8$ & $-7.05 \pm 0.66$ & & \\
$\mathrm{NaH}_{2} \mathrm{PO}_{4}$ solution & $-62.0 \pm 1.0$ & $-8.12 \pm 0.15$ & & +1.39 \\
$\mathrm{NaOH}^{\text {(synthesis of }}$ & $-60.8 \pm 0.6$ & $-7.83 \pm 0.44$ & & \\
$\quad$ libethenite/olivenite) & & & & \\
$\mathrm{CuSO} \mathrm{S}_{4}$ solution & $-60.7 \pm 1.1$ & $-8.54 \pm 0.30$ & +0.17 & \\
$\mathrm{NaOH}$ (synthesis of & $-59.2 \pm 0.9$ & $-7.98 \pm 0.29$ & & \\
$\quad$ brochantite) & & & & \\
\hline
\end{tabular}

Hence, the slope of such a 'mineral' line is the same as the slope of GMWL, but the intercept depends on the fractionation factors, such as those derived in this study. The factors $1000 \ln \alpha$ are a function of temperature (Table 5). The lines that show the dependence of $\mathrm{O}$ and $\mathrm{H}$ isotopes in secondary minerals are shown in Fig. 3 for the temperature $20^{\circ} \mathrm{C}$. The figure shows the expected isotopic composition of the copper minerals that precipitated in equilibrium from rain water. It is obvious that malachite deviates from the other copper secondary mineral. This deviation, however, is only related to a methodological difference. For malachite, the $\delta^{18} \mathrm{O}^{\mathrm{CO}_{2}}$ values were determined (Plumhoff et al., 2021), that is, the isotopic composition of $\mathrm{CO}_{2}$ that escapes from malachite upon dissolution in anhydrous $\mathrm{H}_{3} \mathrm{PO}_{4}$. For the phases investigated in this work, the isotopic composition of the total oxygen was measured.

The isotopic composition of meteoric water at Lubietová and the measured isotopic composition $(\mathrm{O}$ and $\mathrm{H})$ for libethenite and malachite from this site are also shown in Fig. 3 (malachite data taken from Plumhoff et al., 2021). The local meteoric water and the fractionation factors were used to calculate the expected isotopic composition for libethenite and malachite at this site. The results show that libethenite has much higher $\delta^{18} \mathrm{O}$ values than expected, although the $\delta \mathrm{D}$ values conform to the expected ones.

A likely explanation of the discrepancy is the isotopic disequilibrium between phosphate species and the aqueous solution (O’Neil et al., 2003), either in nature or in our experiments. Hence, the oxygen fractionation factors determined in this study should be used with caution. They can be accurate but they can be also subject to systematic error because of the disequilibrium between the aqueous solution and the oxyanions (phosphate, arsenate or sulfate). Another possible explanation is the shift to higher $\delta^{18} \mathrm{O}$ values due to interaction with isotopically
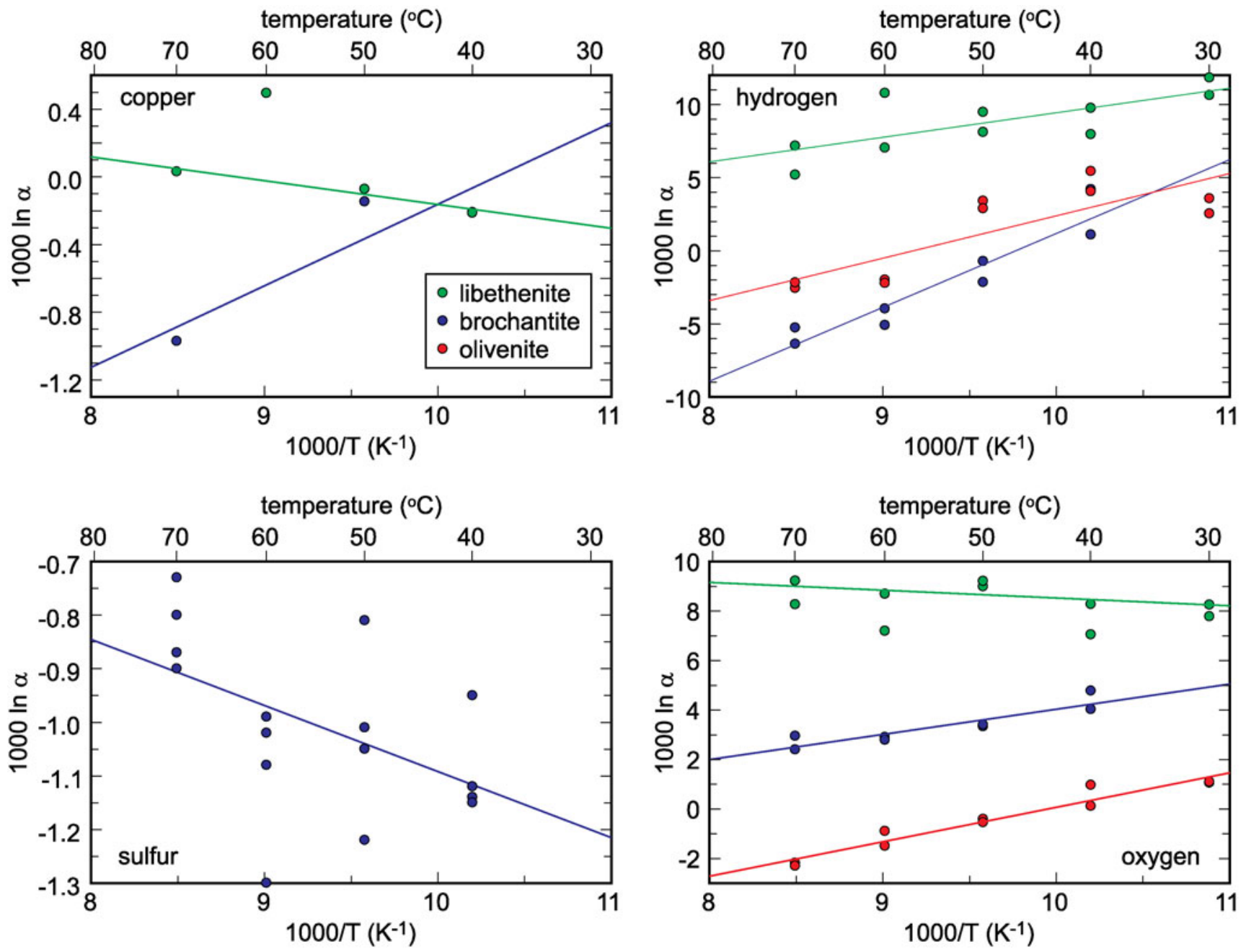

Fig. 2. Isotopic composition of the synthetic samples studied, plotted as a function of temperature and recalculated to the 1000 In $\alpha$ factors. The lines show the fits whose parameters $A$ and $B$ are listed in Table 5. Note that the copper isotope composition for libethenite at $60^{\circ} \mathrm{C}$ was considered to be an outlier and not included in the fits. The copper isotope composition for libethenite and olivenite at $40^{\circ} \mathrm{C}$ overlap and only one symbol is visible. 
Table 5. Empirical parameters $A$ and $B$ for the fractionation equation 1000 In $\alpha=\left(A \times 10^{6} / T^{2}\right)+B$ for different elements in the minerals studied.

\begin{tabular}{llrc}
\hline $\begin{array}{l}\text { Phase } \\
\text { Mineral / Element }\end{array}$ & & $A$ & $B$ \\
\hline Libethenite & Oxygen & $-0.32 \pm 0.16$ & $11.7 \pm 1.6$ \\
& Hydrogen & $1.68 \pm 0.47$ & $-7.4 \pm 4.5$ \\
& Copper & $-0.14 \pm 0.04$ & $1.24 \pm 0.37$ \\
Brochantite & Oxygen & $1.02 \pm 0.15$ & $-6.1 \pm 1.4$ \\
& Hydrogen & $5.05 \pm 0.59$ & $-49.4 \pm 5.5$ \\
& Copper & $0.48 \pm 0.23$ & $-5.0 \pm 2.2$ \\
& Sulfur & $0.12 \pm 0.06$ & $0.14 \pm 0.52$ \\
Olivenite & & & \\
& Oxygen & $1.39 \pm 0.09$ & $-13.9 \pm 0.9$ \\
& Hydrogen & $2.90 \pm 0.58$ & $-26.6 \pm 5.6$ \\
\hline
\end{tabular}

Table 6. Isotopic analyses of natural libethenite crystals from the dumps at L'ubietová-Podlipa.

\begin{tabular}{ccc}
\hline Sample & $\delta \mathrm{D}_{\text {SMOW }}$ & $\delta^{18} \mathrm{O}_{\text {SMOW }}$ \\
\hline Lub-08 & -49.0 & +5.58 \\
Lub-05 & -57.4 & +4.36 \\
Lub-01 & -52.2 & +5.97 \\
\hline
\end{tabular}

heavy country rocks. The isotopic shift of malachite (see also Fig. 3) speaks against this possibility. A more detailed study designed to address these questions at the field site at Lubietová-Podlipa has been started already.

\section{Isotope geothermometry}

Two phases $M$ and $N$ that precipitate from the same parental solution in equilibrium have their isotopic composition related by the equation

$$
T=\left(\frac{\left(A_{M}-A_{N}\right) \times 10^{6}}{B_{N}-B_{M}-\delta_{N}+\delta_{M}}\right)^{0.5}
$$

For example, for the hydrogen isotopes in the pair libethenitemalachite, the equation is

$$
T=\left(\frac{-3.15 \times 10^{6}}{14.9-\delta D_{\text {libethenite }}+\delta D_{\text {malachite }}}\right)^{0.5}
$$

Using the isotopic composition of libethenite (Table 6, this work) and malachite (Plumhoff et al., 2021) from LubietováPodlipa, the calculated formation temperature is $80-90^{\circ} \mathrm{C}$. Participation of low-temperature hydrothermal fluids in the ore oxidation has been proposed and documented before (Haßler et al., 2014). As mentioned above, a larger study intended to elucidate the origin of the oxidation zone at Lubietová-Podlipa has been started. One of the questions that should be attended and answered is if such elevated temperatures are feasible within the geological and mineralogical context of the site.

In order to use such an isotopic geothermometer, the evidence of coeval formation of the two minerals must be firmly established. Textural observations must clearly witness that the two

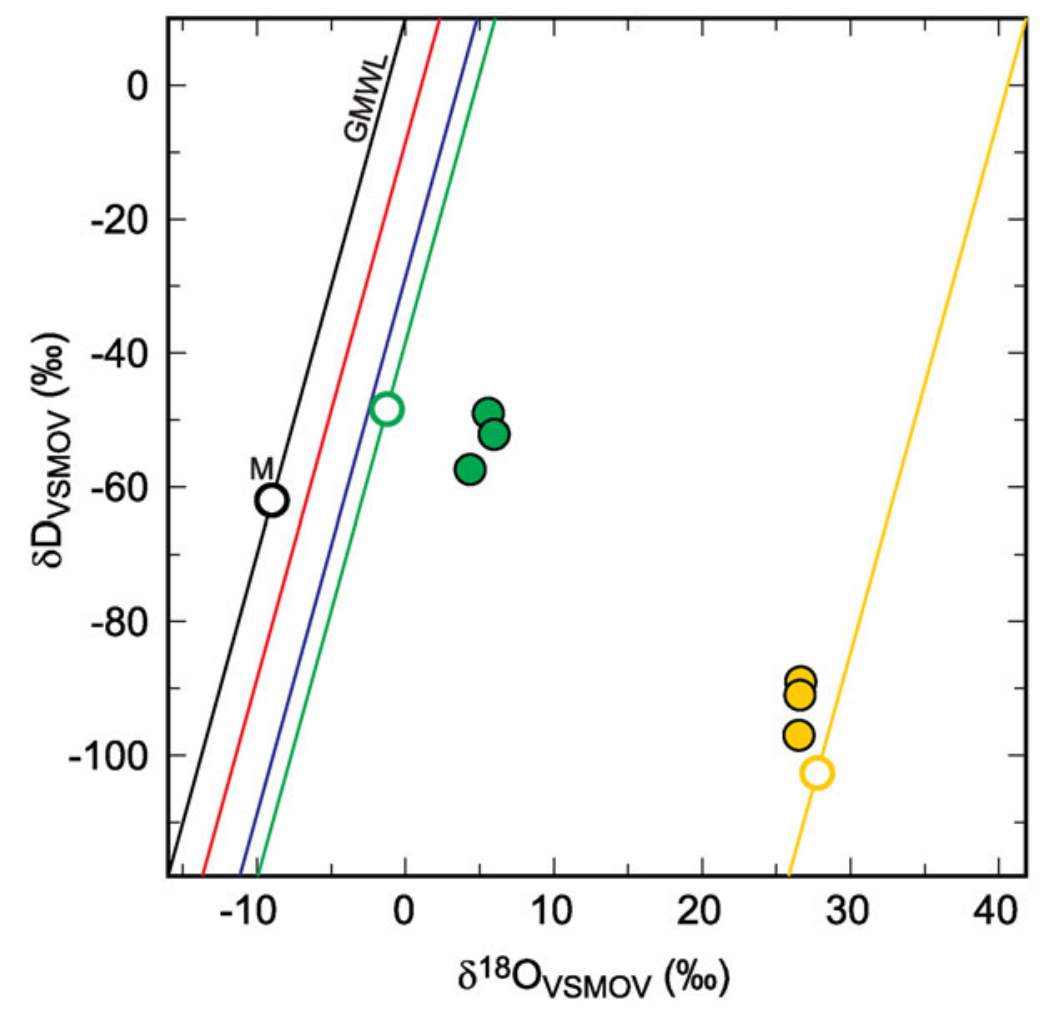

\begin{tabular}{ll}
\hline & $\begin{array}{l}\text { global meteoric water line } \\
\text { malachite* line } \\
\text { libethenite line }\end{array}$ \\
\hline & $\begin{array}{l}\text { olivenite line } \\
\text { brochantite line }\end{array}$ \\
$\bigcirc \quad \begin{array}{l}\text { meteoric water at L'ubietová } \\
\text { expected composition for } \\
\text { malachite }\end{array}$ \\
measured composition for \\
malachite \\
expected composition for \\
libethenite \\
measured composition for \\
libethenite
\end{tabular}

Fig. 3. Global meteoric water line (GMWL), isotopic composition of meteoric water (M) at L'ubietová, and mineral lines calculated for a set of secondary copper minerals. The diagram also shows the isotopic composition of malachite* and libethenite, calculated from the composition of meteoric water and experimentally determined fractionation factors. The expected (calculated) isotopic composition is compared to the measured data from L'ubietová. All data for malachite from Plumhoff et al. (2021). The asterisk for the malachite isotopic composition means that $\delta^{18} \mathrm{O}$ values in this case are related only to the $\mathrm{CO}_{2}$ liberated during dissolution of malachite in $\mathrm{H}_{3} \mathrm{PO}_{4}$. For the minerals studied in this work, total oxygen was measured. 

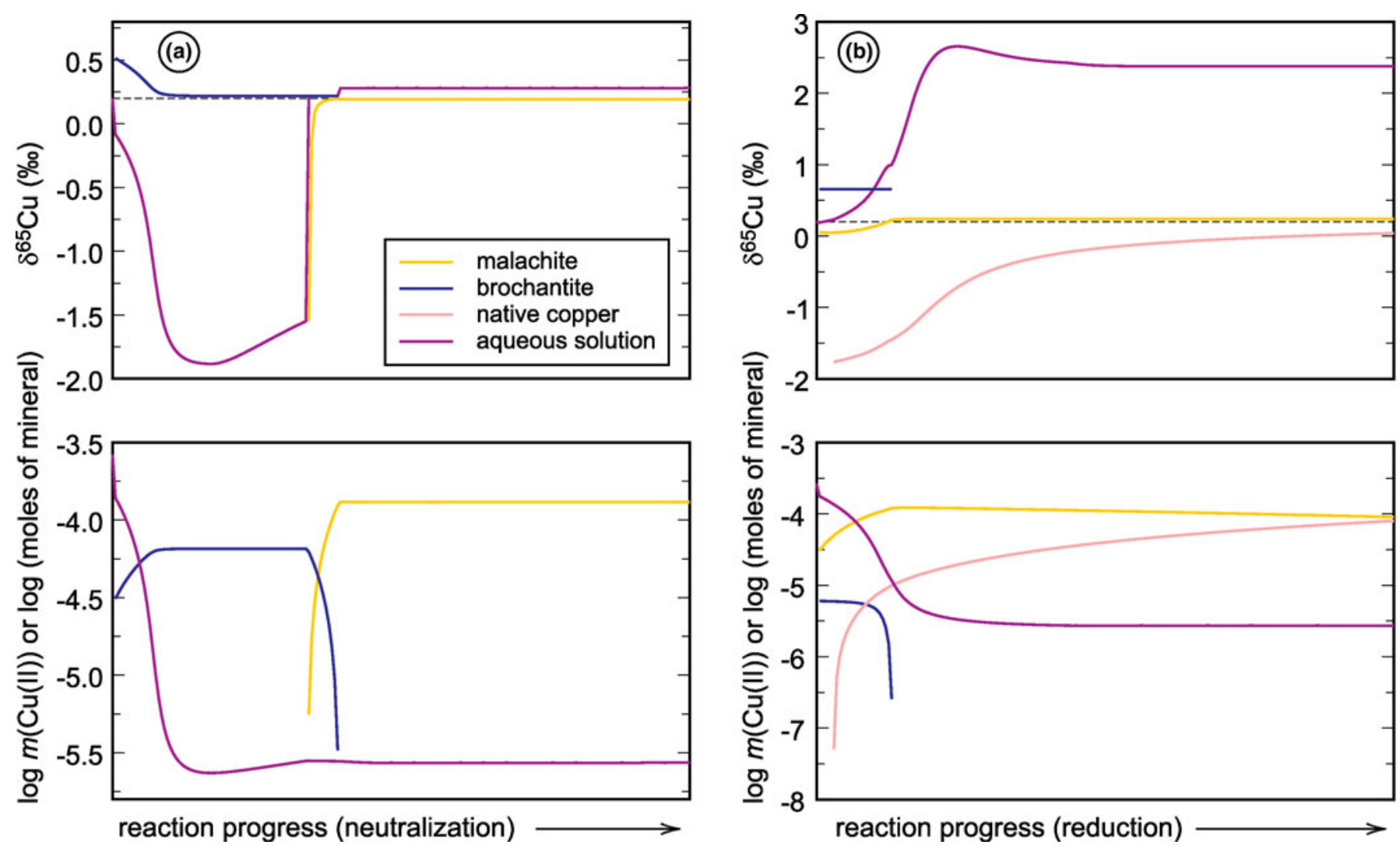

Fig. 4. Graphical representations of the forward models that simulate (a) neutralisation and (b) reduction of a neutral mine drainage solution rich in copper (see Majzlan et al., 2018 and Supplementary material). Chemical speciation is expressed in the bottom panels as number of moles of minerals or Cu(II) molality of the aqueous solution. The upper panels show the evolution of the $\delta^{65} \mathrm{Cu}$ isotopic composition of each reservoir. For details, see text.

minerals precipitated simultaneously, from the same fluid. Equilibrium can be only assumed as it is usually very difficult to prove. Hence, in deposits with co-eval malachite, brochantite, libethenite, or olivenite, precipitation temperature can be determined precisely and linked to the formation processes of the secondary minerals.

\section{Fluctuations in isotopic composition of copper}

The $\delta^{65} \mathrm{Cu}$ values do not change significantly in reactions which do not involve redox changes of copper (e.g. Plumhoff et al., 2021). When considering malachite, the mineral should have slightly lower $\delta^{65} \mathrm{Cu}$ than the parental solution. The same holds for libethenite, but not for brochantite (Table 5). These fractionation factors are small in comparison to the magnitude of fractionation with redox changes (Mathur and Fantle, 2015, Plumhoff et al., 2021). It is therefore of interest to perform simple calculations in order to determine the possible variations in $\delta^{65} \mathrm{Cu}$ of the fluids when secondary copper minerals precipitate.

In systems that contain little $\mathrm{Cu}$ or are strongly $\mathrm{Cu}$-limited (e.g. $\mathrm{Cu}<<\mathrm{S}$ ), copper may precipitate essentially completely out of the solution. Mine drainage systems, on the other hand, may contain sufficient copper so that even after precipitation, the fluids will contain a substantial copper load with a distinct $\delta^{65} \mathrm{Cu}$ value. A neutral mine drainage system in Lubietová was investigated by Majzlan et al. (2018) and one of the analyses of the copper-contaminated water was adopted for further calculations.
Two forward simulations were carried out. One of them involves dissolution of calcite and increase of $\mathrm{pH}$, even though the initial $\mathrm{pH}$ was already 6.4. This simulation is referred to as neutralisation hereafter. The other simulation is based on addition of methane into the aqueous solution, causing gradual reduction of the aqueous species. This simulation is referred to here as reduction. The simulations were carried out with the program PHREEQC (Parkhurst and Appelo, 1999) and the molar amounts of minerals that precipitate or dissolve were written to the output files. A self-written program used these results as an input and calculated the copper isotopic composition of each phase, including the aqueous phase. The calculations were done with the assumption that minerals crystallise in equilibrium with the aqueous phase (according to the fractionation factors in Table 5). Mineral dissolution, on the other hand, was considered to be isotopically congruent, without isotopic changes.

The starting solutions in both simulations have $\delta^{65} \mathrm{Cu}$ of $+0.2 \%$. During neutralisation, brochantite precipitates initially and drives the isotopic composition of the fluid to negative values, almost $-1.7 \%$. Afterwards, brochantite dissolves and malachite precipitates and the isotopic composition of the fluid returns back to almost the initial value. If, in Nature, the calcite dissolution proceeds slowly and the fluid is removed from the precipitating minerals, it can be modified substantially from its original state, namely isotopically much lighter than at the beginning.

During reduction, a small amount of brochantite precipitates initially but dissolves quickly as the reaction proceeds. Malachite precipitates and remains during the simulation, even though the mineral dissolves slowly. Reduction causes 
precipitation of native copper whose amount increases with the progress of the reaction. If such reactions are allowed to proceed further, covellite will form and take up the remaining copper from the solution (in that case, final molality of $\mathrm{Cu}$ (II) is $10^{-19}$ ). In the simulation presented here, however, covellite did not form. The fractionation factor for native copper was taken from Qi et al. (2019), noting that this factor shows unusual behaviour at low temperatures and needs to be verified by further studies. Precipitation of native copper causes an increase of the original $\delta^{65} \mathrm{Cu}$ of $+0.2 \%$ to around $+2.5 \%$. Hence, such reactions can cause a substantial shift in the isotopic composition of the fluid, with appreciable remaining copper in the solution.

These two simple examples document the magnitude of $\delta^{65} \mathrm{Cu}$ changes induced by $\mathrm{pH}$ or redox changes in an oxidation zone or a mine drainage system. These models do not take into account adsorption of copper onto surfaces of minerals, its association with organic matter, or the action of microorganisms. Even with no redox changes taking place, isotopic shifts on the order of $1 \%$ or slightly more can be encountered. Of course, redox changes will cause even larger isotopic shifts.

Acknowledgements. This work is dedicated to Pete Williams for his lifelong contribution to our understanding of secondary minerals and oxidation zones. We are thankful to Erik Melchiorre and an anonymous reviewer for the constructive criticism. We thank Stefanie Notz, Franziska Meißner, Kevin Kretschmer and Felix Tost for the help with the syntheses. The work presented here was supported financially by Deutsche Forschungsgemeinschaft grant MA 3927/26-1.

Supplementary material. To view supplementary material for this article, please visit https://doi.org/10.1180/mgm.2021.77

\section{References}

Bowell R.J. (2014) Hydrogeochemistry of the Tsumeb Deposit: Implications for arsenate mineral stability. Pp. 589-627 in: Arsenic: Environmental Geochemistry, Mineralogy, and Microbiology (R.J. Bowell, C.N. Alpers, H.E. Jamieson, D.K. Nordstrom and J. Majzlan, editors). Reviews in Mineralogy and Geochemistry, 79. Mineralogical Society of America and the Geochemical Society, Chantilly, Virginia, USA.

Cordsen A. (1978) A crystal-structure refinement of libethenite. The Canadian Mineralogist, 16, 153-157.

Glynn P.D. (1991) MBSSAS: A code for the computation of Margules parameters and equilibrium relations in binary solid-solution aqueous-solution systems. Computers and Geosciences, 17, 907-966.

Glynn P.D. (2000) Solid-solution solubilities and thermodynamics: Sulfates, carbonates and halides. Pp. 481-511 in: Sulfate Minerals: Crystallography, Geochemistry, and Environmental Significance (C.N. Alpers, J.L. Jambor and D.K. Nordstrom, editors). Reviews in Mineralogy, 40. Mineralogical Society of America, Washington DC.

Haßler K., Taubald H. and Markl G. (2014) Carbon and oxygen isotope composition of $\mathrm{Pb}-, \mathrm{Cu}$ - and $\mathrm{Bi}$-carbonates of the Schwarzwald mining district: Carbon sources, first data on bismutite and the discovery of an oxidation zone formed by ascending thermal water. Geochimica et Cosmochimica Acta, 133, 1-16.

Helliwell M. and Smith J.V. (1997) Brochantite. Acta Crystallographica, C53, 1369-1371.

Karlén C., Wallinder I.O., Heijerickand D.G. and Leygraf C. (2002) Runoff rates, chemical speciation and bioavailability of copper released from naturally patinated copper. Environmental Pollution, 120, 691-700.

Li C., Yang H. and Downs R.T. (2008) Redetermination of olivenite from an untwinned single-crystal. Acta Crystallographica, E64, i60-i61.

Lippmann F. (1980) Phase diagrams depicting aqueous solubility of binary mineral systems. Neues Jahrbuch für Mineralogie, Abhandlungen, 139, 1-25.

Livingston R.A. (1991) Influence of the environment on the patina of the Statue of Liberty. Environmental Science \& Technology, 25, 1400-1408.
Magalhães M.C.F., de Jesus J.D.P. and Williams P.A. (1986) Stability constants and formation of $\mathrm{Cu}(\mathrm{II})$ and $\mathrm{Zn}$ (II) phosphate minerals in the oxidized zone of base metal orebodies. Mineralogical Magazine, 50, 33-39.

Magalhães M.C.F., de Jesus J.D.P. and Williams P.A. (1988) The chemistry of formation of some secondary arsenate minerals of $\mathrm{Cu}(\mathrm{II}), \mathrm{Zn}(\mathrm{II})$ and $\mathrm{Pb}$ (II). Mineralogical Magazine, 52, 679-690.

Majzlan J. (2020) Processes of metastable-mineral formation in oxidation zones and mine wastes. Mineralogical Magazine, 84, 367-375, https://doi. org/10.1180/mgm.2020.19

Majzlan J., Števko M., Chovan M., Luptáková J., Milovská S., Milovský R., Jeleň S., Sýkorová M., Pollok K., Göttlicher J. and Kupka D. (2018) Mineralogy and geochemistry of the copper-dominated neutral mine drainage at the $\mathrm{Cu}$ deposit Lubietová-Podlipa (Slovakia). Applied Geochemistry, 92, 59-70.

Mathur R. and Fantle M.S. (2015) Copper isotopic perspectives on supergene processes: Implications for the global Cu cycle. Elements, 11, 323-329.

Mathur R., Ruiz J., Titley S., Liermann L., Buss H. and Brantley S.L. (2005) Cu isotopic fractionation in the supergene environment with and without bacteria. Geochimica et Cosmochimica Acta, 69, 5233-5246.

Mathur R., Titley S., Hart G., Wilson M., Davignon M. and Zlatos C. (2009) The history of the United States cent revealed through copper isotope fractionation. Journal of Archaeological Science, 36, 430-433.

Melchiorre E.B., Criss R.E. and Rose T.P. (1999) Oxygen and carbon isotope study of natural and synthetic malachite. Economic Geology, 94, 245-260.

O'Neil J.R., Clayton R.N. and Mayeda T.K. (1969) Oxygen fractionation in divalent metal carbonates. Journal of Chemical Physics, 51, 5547-5558.

O'Neil J.R., Vennemann T.W. and McKenzie W.F. (2003) Effects of speciation on equilibrium fractionations and rates of oxygen isotope exchange between $\left(\mathrm{PO}_{4}\right)_{\mathrm{aq}}$ and $\mathrm{H}_{2} \mathrm{O}$. Geochimica et Cosmochimica Acta, 67, 3135-3144.

Parkhurst D.L. and Appelo C.A.J. (1999) User's guide to PHREEQC (Version 2) - a computer program for speciation, batch-reaction, one-dimensional transport, and inverse geochemical calculations. USGS Water-Reources. Investigations Report, 99-4259, 312 pp, US Geological Survey, Reston, Virginia, USA.

Plumhoff A.M., Mathur R., Milovský R. and Majzlan J. (2021) Fractionation of the copper, oxygen and hydrogen isotopes between malachite and aqueous phase. Geochimica et Cosmochimica Acta, 300, 246-257, https://doi.org/10. 1016/j.gca.2021.02.009

Portales R.L., Jiménez G.C., Michel H.C., Amador D.O.R., Mikuš K.V., Kump P. and de la Rosa G. (2015) Understanding copper speciation and mobilization in soils and mine tailings from "Mineral La Aurora" in central Mexico: Contributions from synchrotron techniques. Boletín de la Sociedad Geológica Mexicana, 67, 447-456.

Qi H., Coplen T.B., Gehre M., Vennemann T.W., Brand W.A., Geilmann H., Olack G., Bindeman I.N., Palandri J., Huang L. and Longstaff F.J. (2017) New biotite and muscovite isotopic reference materials, USGS57 and USGS58, for $\beta^{2} \mathrm{H}$ measurements - A replacement for NBS 30. Chemical Geology, 467, 89-99.

Qi D., Behrens H., Lazarov M. and Weyer S. (2019) Cu isotope fractionation during reduction processes in aqueous systems: evidences from electrochemical deposition. Contributions to Mineralogy and Petrology, 174, 37.

Sharp, Z. (2017) Principles of Stable Isotope Geochemistry, $2^{\text {nd }}$ Edition. https:// doi.org/10.25844/h9q1-0p82

Siidra O.I., Krivovichev S.V., Chukanov N.V., Pekov I.V., Magganas A., Katerinopoulos A. and Voudouris P. (2011) The crystal structure of $\mathrm{Pb}_{5}\left(\mathrm{As}^{3+} \mathrm{O}_{3}\right) \mathrm{Cl}_{7}$ from ancient slags of Lavrion, Greece - $\mathrm{A}$ novel $\mathrm{Pb}(\mathrm{II})$ chloride arsenite. Mineralogical Magazine, 75, 337-345.

Sracek O., Mihaljevič M., Kříbek B., Majer V. and Veselovský F. (2010) Geochemistry and mineralogy of $\mathrm{Cu}$ and $\mathrm{Co}$ in mine tailings at the Copperbelt, Zambia. Journal of African Earth Sciences, 57, 14-30.

Williams P.A. (1990) Oxide Zone Geochemistry. Ellis Horwood, New York, 286 pp.

Zhang Y., Bao Z., Lv N., Chen K., Zong C. and Yuan H. (2020) Copper isotope ratio measurements of $\mathrm{Cu}$-dominated minerals without column chromatography using MC-ICP-MS. Frontiers in Chemistry, 8, 609.

Zhu X.K., O’Nions R.K., Guo Y., Belshaw N.S. and Rickard D. (2000) Determination of natural $\mathrm{Cu}$-isotope variation by plasma-source mass spectrometry; implications for use as geochemical tracers. Chemical Geology, 163, 139-149. 